\title{
Nano-ZnO Catalyzed Green and Efficient One-Pot Four-Component Synthesis of Pyranopyrazoles
}

\author{
Sunil U. Tekale, ${ }^{1}$ Sushma S. Kauthale, ${ }^{2}$ Kavita M. Jadhav, ${ }^{2}$ and Rajendra P. Pawar ${ }^{2}$ \\ ${ }^{1}$ Department of Chemistry, Shri Muktanand College, Gangapur, Maharashtra 431 109, India \\ ${ }^{2}$ Department of Chemistry, Deogiri College, Station Road, Aurangabad, Maharashtra 431 005, India \\ Correspondence should be addressed to Rajendra P. Pawar; rppawar@yahoo.com
}

Received 15 May 2013; Accepted 29 June 2013

Academic Editor: Hakan Arslan

Copyright (c) 2013 Sunil U. Tekale et al. This is an open access article distributed under the Creative Commons Attribution License, which permits unrestricted use, distribution, and reproduction in any medium, provided the original work is properly cited.

\begin{abstract}
An efficient zinc oxide nanoparticle catalyzed one-pot, four-component synthesis of 6-amino-3-methyl-5-cyano-4-aryl-1,4dihydropyrano[2,3-c]pyrazoles from aromatic aldehyde, malononitrile, ethyl acetoacetate, and hydrazine hydrate in aqueous medium is described. Since water was employed as the reaction medium, it serves as a green route for the synthesis of pyrano[2,3c]pyrazoles. The advantages associated with the present protocol include nonchromatographic purification technique, use of recyclable heterogeneous nano- $\mathrm{ZnO}$ catalyst in aqueous medium, and short reaction time. It combines successfully the synergistic effect of green chemistry with nanocatalysis.
\end{abstract}

\section{Introduction}

Multicomponent reactions (MCR), also referred to as the multicomponent assembly processes (MCAP), are the convergent, one-pot reactions of more than two simple precursors. These act as a gateway for providing an easy access to a wide range of functionally novel and complex heterocyclic molecules with high selectivity [1]. Besides routine multistep synthesis, MCRs are superior. In recent years, MCRs came into light over routine multistep synthesis counterparts owing to their atom economy, energy efficiency, lower costs, short reaction time, environmental friendly nature, and simpler purification techniques. Hence nowadays, synthesis of novel heterocyclic compounds by MCR approach has became not only an integral part of pharmaceutical chemistry but also an important tool in the discovery of new potent life-saving drug candidates [2]. Thus the study of multicomponent reactions has attracted tremendous attention of scientific community across the world to develop novel and effective protocols [3].

With the growing concern over environment pollution and related societal health problems, green chemistry concept is emerging as one of the important tools in the development of environmentally benign chemical processes and clean technologies [4] including generation of solvent-free protocols along with replacement of easily volatile organic solvents by water as a green reaction medium [5]. Water is nonhazardous, inexpensive, abundant, and ecofriendly in nature having high boiling point. Furthermore, owing to typical reactivity and selectivity, reactions are preferred in aqueous medium. Reactions in aqueous medium not only possess negative activation volume [6] but also help in controlling exothermic reactions. Hence organic synthesis in aqueous medium is preferred from environmental as well as from economical point of view.

Heterogeneous catalysts are always superior to their homogeneous counterparts in terms of many aspects such as operational simplicity, reusability, environmental compatibility, and high selectivity. In current time along with green chemistry, nanoparticulate heterogeneous solid acidbase catalysts have received notable attention in organic transformations on the ground of their ability to enhance faster rates of organic reactions, high catalytic activity, reusability, and higher yield of products which is due to their ability to afford high particle size-to-volume ratio along with greater surface area. Henceforth utility of these catalysts is gaining significant attention and becomes a more potential thrust area for the synthesis of highly functionalized pharmaceutically significant heterocyclic compounds [7]. 


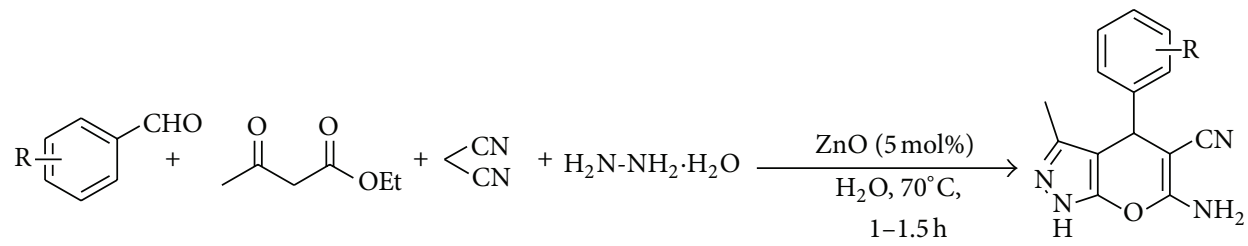

Scheme 1: ZnO nanoparticle catalyzed one-pot four-component green synthesis of pyranopyrazoles.

Thus, water-mediated multicomponent reactions using heterogeneous catalysts have become the popular targets for synthetic organic chemists. In present work we have employed water as the clean, environment-friendly reaction medium, rather than the use of organic solvent [8] for the synthesis of $4 H$-pyrano[2,3-c]pyrazoles utilizing zinc oxide nanoparticle catalyzed multicomponent reaction of aromatic aldehyde, malononitrile, ethyl acetoacetate, and hydrazine hydrate.

$\mathrm{ZnO}$ is a well-known wide bandgap $(\mathrm{Eg} \sim 3.3 \mathrm{eV}$ at $300 \mathrm{~K}$ ) material in the field of electronics and nanotechnology since 1935 (Bunn, 1935). ZnO functions as a heterogeneous catalyst which can be easily separated from the reaction mixture and reused several times. Owing to unique and novel characteristic properties like polar surface, noncorrosiveness, reusability, and ability to generate clean products, nowadays nano- $\mathrm{ZnO}$ is extensively recruited as a powerful catalyst for numerous organic transformations by various researchers for exploring its synthetic utility preferably under solventfree conditions or in aqueous medium $[9,10]$. These facts encouraged us to use $\mathrm{ZnO}$ nanoparticles for the green synthesis of pyranopyrazoles.

Pyrano[2,3-c]pyrazoles are the medicinally privileged compounds with a wide spectrum of biomedical and pharmaceutical applications [11]. Compound (a) of Figure 1 with pyrano[2,3-c]pyrazole scaffold in its structure has been documented as potential inhibitor of human Chk1 kinase [12]. Furthermore, the biological potential of compound (b) of Figure 1 is better reported in the literature [13]. 4H-pyrano[2,3-c]pyrazole derivatives possess significant biological activities such as antiinflammatory, molluscicidal, insecticidal, antitumor, and anticancer properties [14, 15]. They also have applications as pharmaceutical ingredients and biodegradable agrochemicals [16].

On account of these biological activities the synthesis of these compounds has become an interesting area for synthetic organic chemists. These compounds can be synthesized by three-component reaction of 2-pyrazolin-5-ones, malononitrile, and aromatic aldehydes or a four-component reaction of readily available starting materials, namely hydrazine hydrate, ethyl acetoacetate, malononitrile, and aromatic aldehydes.

Khurana et al. [17] reported a three-component approach for the synthesis of pyranopyrazoles using 1-butyl-3methylimidazolium tetrafluoroborate under sonication bath which required separation of the ionic liquid as an additional task. Nonrecyclable catalyst-triethylbenzylammonium chloride (TEBA) - was used by Shi et al. [18] which required longer reaction time. The three-component synthesis catalyzed by $p$-dodecylbenzenesulfonic acid (DBSA) was<smiles></smiles>

(a)<smiles>CCOC(=O)CC1(C)C(C#N)=C(N)Oc2n[nH]c(C)c21</smiles>

(b)
FIGURE 1: Some biologically potent pyranopyrazoles.

reported by Jin et al. [19]. Four component syntheses were carried out by several researchers using different protocols such as heteropoly acids [20], alumina [21], use of additional microwave or ultrasound irradiation $[22,23]$, use of toxic base such as piperidine [13], and nonrecoverable molecular iodine [24].

Although the reported methods are effective, many of the existing methodologies suffer from several drawbacks which require comparatively longer time, higher temperature, use of toxic piperazine and piperidine bases, tedious and cumbersome processes in ionic liquid mediated synthesis, use of organic solvents [8] rather than aqueous medium, environment compatibility using toxic and expensive catalysts, lack of recyclability, and so forth. The use of ultrasound or microwave assisted synthesis, although fast, requires additional use of sonicator or microwave oven and may not be suitable for large-scale synthesis. So despite of the available literature for the synthesis of pyranopyrazoles, simple, efficient, and environmentally benign approaches are still demanding. As a part of our ongoing research in the field of developing new routes for the synthesis of various heterocyclic compounds using nanocatalysts [25]; in present work we demonstrated nanoparticles of zinc oxide as an efficient, reusable, heterogeneous catalyst for green and scalable synthesis of 6-amino-3-methyl-5-cyano-4-aryl-1, 4dihydropyrano[2,3-c] pyrazoles by four-component reaction in aqueous medium (Scheme 1).

\section{Result and Discussion}

The reaction between hydrazine hydrate, ethyl acetoacetate (EAA), malononitrile, and benzaldehyde was chosen as a model condensation reaction for optimizing the various reaction parameters. Initially, the reaction was tried in presence of $5 \mathrm{~mol} \%$ of $\mathrm{ZnO}$ nanoparticles at room temperature in aqueous medium. But the reaction could not complete even after $4-5 \mathrm{~h}$. When the temperature of the reaction 


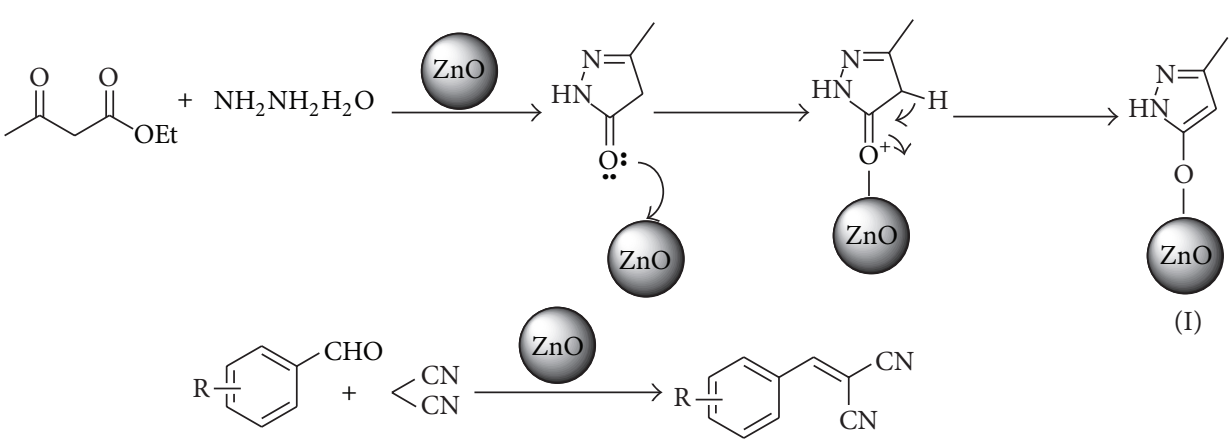

(II)

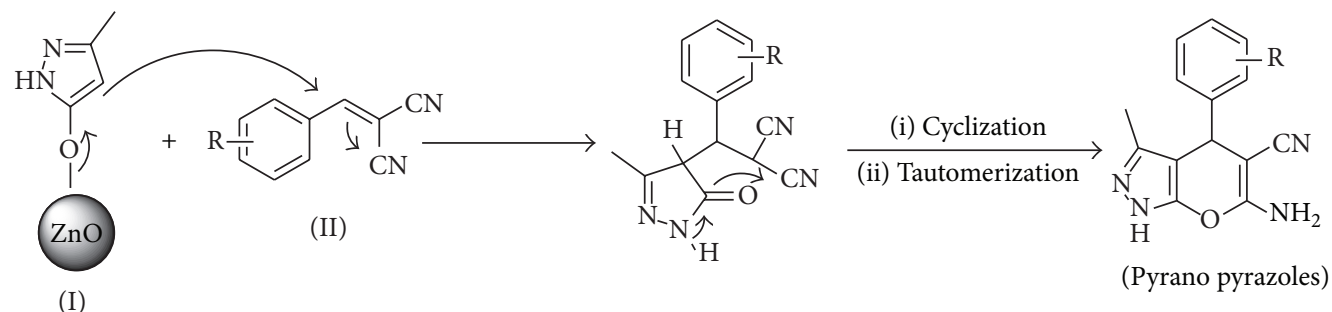

FIGURE 2: Plausible mechanism for the $\mathrm{ZnO}$ nanoparticle catalyzed four-component synthesis of pyranopyrazoles.

was raised to $70^{\circ} \mathrm{C}$, TLC showed a drastic change wherein the intermediates were converted into the desired products within $1 \mathrm{~h}$. Further increase in the temperature to $100^{\circ} \mathrm{C}$ could not enhance yield of the corresponding products significantly (Table 2). Also the effect of several solvents such as DCM, $\mathrm{ACN}, \mathrm{THF}, \mathrm{EtOH}$, and $\mathrm{MeOH}$ under reflux condition did not show any good yields (Table 2). The comparative results showed that Millipore water was observed to be superior as compared to the common organic solvents (Table 2). This suggests that the solvent polarity also contributes a significant role to the synthesis of pyranopyrazoles.

In addition to the above, the effect of catalyst concentration and temperature was also studied which indicated that $5 \mathrm{~mol} \%$ of the zinc oxide (with $5,10,15 \mathrm{~mol} \%$ of the catalyst in aqueous medium giving 94, 95, 95\% of the corresponding product in case of benzaldehyde) at $70^{\circ} \mathrm{C}$ temperature was sufficient enough to catalyze the reaction. After optimizing the reaction conditions, different aldehydes with electrondonating and electron-withdrawing groups were investigated to check the feasibility of this protocol whose results are tabulated in (Table 1).

Almost all the employed aldehydes resulted in goodto-excellent yield of the corresponding products. Studies revealed that aldehydes having electron-withdrawing substituents reacted faster and gave better yield of the product as compared to the aldehydes with electron-donating substituents. In spectral data the IR spectrum (for entry 1) exhibited sharp bands at $3410,3356 \mathrm{~cm}^{-1}\left(\mathrm{NH}_{2}\right), 2190 \mathrm{~cm}^{-1}$ $(\mathrm{CN})$, supporting the formation of products. Since the product, pyranopyrazole, was insoluble in the aqueous medium, initially it was filtered off along with the catalyst. The residue was washed with hot ethanol and again filtered. The filtrate was allowed to stand at room temperature to get the crystals of product which were subsequently washed with a mixture of ( $30 \%$ EA: hexane) to afford the pure product. Furthermore, the catalyst can be recycled several times without significant loss of its catalytic activity (Table 3 ).

Thus, this protocol provides an easy access of pure products without using any chromatographic techniques. The products were simply purified by recrystallization from ethanol followed by washing with a mixture of EA: hexane. Comparatively high yield and reduced reaction time can be explained on the basis of large surface area afforded by the catalyst due to smaller particle size (50-100 $\mathrm{nm}$ as clearly seen from the TEM images).

The plausible mechanism for $\mathrm{ZnO}$ nanoparticle catalyzed synthesis of pyranopyrazoles is depicted in Figure 2. Initially the reaction between ethyl acetoacetate and hydrazine forms the pyrazolone (I). Simultaneously there is formation of arylidene malononitrile (II) by the Knoevenagel condensation between aldehyde and malononitrile. Michael addition of pyrazolone (I) to arylidene malononitrile (II), followed by cyclization and then tautomerization, affords the pyranopyrazole.

\section{Conclusion}

In summary we have developed $\mathrm{ZnO}$ nanoparticle catalyzed efficient, one-pot, four-component coupling reaction of aromatic aldehyde, malononitrile, ethyl acetoacetate, and hydrazine hydrate in aqueous medium to access substituted pyranopyrazoles in higher yields within short time. The present protocol has several advantages not only in terms of yield but also applicability for large-scale synthesis using water as the green reaction medium in short reaction time. Operational simplicity, recyclability of the catalyst, and atom economical and environmentally benign nature make it an attractive process. It meets the requirements of clean organic reactions in water as well as the vigorously increasing applications of nanocatalysts in organic synthesis. 
TABLE 1: ZnO nanoparticle catalyzed one-pot four-component synthesis of pyranopyrazoles in aqueous medium.

\begin{tabular}{|c|c|c|c|c|c|}
\hline Entry & Aldehyde & Product & Time (min) & Yield (\%) & M.P. $\left({ }^{\circ} \mathrm{C}\right)$ \\
\hline 1 & $\mathrm{C}_{6} \mathrm{H}_{5}$ & & 60 & 94 & $243-245[20]$ \\
\hline 2 & $4-\mathrm{Cl}-\mathrm{C}_{6} \mathrm{H}_{4}$ & & 60 & 90 & $233-235$ [22] \\
\hline 3 & $4-\mathrm{NMe}_{2}-\mathrm{C}_{6} \mathrm{H}_{4}$ & & 70 & 86 & $234-235$ [13] \\
\hline 4 & $4-\mathrm{SMe}-\mathrm{C}_{6} \mathrm{H}_{4}$ & & 70 & 88 & $242-244$ \\
\hline 5 & $4-\mathrm{OH}-\mathrm{C}_{6} \mathrm{H}_{4}$ & & 90 & 82 & $222-224$ [22] \\
\hline 6 & $2-\mathrm{Cl}-\mathrm{C}_{6} \mathrm{H}_{4}$ & & 80 & 89 & $244-246$ [22] \\
\hline
\end{tabular}


TABLe 1: Continued.

\begin{tabular}{|c|c|c|c|c|c|}
\hline Entry & Aldehyde & Product & Time (min) & Yield (\%) & M.P. $\left({ }^{\circ} \mathrm{C}\right)$ \\
\hline 7 & $4-\mathrm{Me}-\mathrm{C}_{6} \mathrm{H}_{4}$ & & 70 & 90 & 206-207 [21] \\
\hline 8 & $4-\mathrm{Br}-\mathrm{C}_{6} \mathrm{H}_{4}$ & & 65 & 85 & $179-180$ [23] \\
\hline 9 & $4-\mathrm{NO}_{2}-\mathrm{C}_{6} \mathrm{H}_{4}$ & & 90 & 87 & 149-151 [23] \\
\hline 10 & $4-\mathrm{OMe}-\mathrm{C}_{6} \mathrm{H}_{4}$ & & 70 & 90 & $211-212[22]$ \\
\hline 11 & $\begin{array}{c}\text { 3-OMe-4-OH- } \\
\mathrm{C}_{6} \mathrm{H}_{3}\end{array}$ & & 80 & 91 & $234-236$ [21] \\
\hline 12 & $3-\mathrm{NO}_{2} \mathrm{C}_{6} \mathrm{H}_{4}$ & & 90 & 87 & $214-216$ [20] \\
\hline
\end{tabular}


TABle 1: Continued.

\begin{tabular}{lllll}
\hline Entry & Aldehyde & Time $(\mathrm{min})$ & Yield $(\%)$ & M.P. $\left({ }^{\circ} \mathrm{C}\right)$ \\
\hline 13 & 2 -Furyl & 80 & 86 & $217-219[20]$
\end{tabular}

Reactions were tried on aldehyde $(1 \mathrm{mmol})$, ethyl acetoacetate $(1 \mathrm{mmol})$, malononitrile $(1 \mathrm{mmol})$ in water $(1 \mathrm{~mL})$ using $\mathrm{ZnO}(5 \mathrm{~mol} \%)$ nanoparticles.

TABLE 2: Effect of $\mathrm{ZnO}$ nanoparticle solvent on the synthesis of pyranopyrazoles.

\begin{tabular}{lccc}
\hline Entry & Solvent & Temp. & Yield $^{\circledR}(\%)$ \\
\hline 1 & Dichloromethane & Reflux & 32 \\
2 & Acetonitrile & Reflux & 45 \\
3 & Tetrahydrofuran & Reflux & 52 \\
4 & Ethanol & Reflux & 67 \\
5 & Methanol & Reflux & 62 \\
6 & Millipore water & r.t. & 65 \\
7 & Millipore water & $70^{\circ} \mathrm{C}$ & 94 \\
8 & Millipore water & Reflux & 96 \\
${ }^{\circledR}$ Yield
\end{tabular}

${ }^{\circledR}$ Yield obtained with benzaldehyde and $5 \mathrm{~mol} \%$ amount of $\mathrm{ZnO}$ after $60 \mathrm{~min}$.

TABLE 3: Recycle study of ZnO nanocatalyst.

\begin{tabular}{lcccc}
\hline Run & 1 & 2 & 3 & 4 \\
Yield $^{\mathrm{b}}(\%)$ & 94 & 90 & 87 & 85 \\
\hline
\end{tabular}

${ }^{\mathrm{b}}$ Yield in case of benzaldehyde.

Thus the present protocol helps in generating molecular complexity and developing diversity through the one-pot four-component reactions.

\section{Experimental Protocols}

All the chemicals required were purchased from Aldrich or SD Fine Chemical companies and used without further purification. Melting points were recorded in capillaries open at one end and were uncorrected. ${ }^{1} \mathrm{H}$ NMR spectra were recorded using DMSO- $\mathrm{d}_{6}$ solvent on $400 \mathrm{MHz}$ Varian spectrophotometer with TMS as an internal standard, and chemical shifts $(\delta)$ are expressed in ppm. Mass spectra were scanned on Shimadzu mass analyzer with EI $70 \mathrm{eV}$. The catalyst used was Aldrich made. X-ray diffraction pattern was studied on Brucker axe diffractometer (model D8 Advance (German)). TEM images were recorded on the transmission electron microscope instrument (TECNAI G2 20 U-TWIN, FEI, The Netherlands). Infrared spectra were recorded on Bruker Vector 22 FTIR spectrophotometer using KBr discs.

4.1. General Procedure for the Synthesis of Pyranopyrazoles. To a magnetically stirred aqueous solution of ethyl acetoacetate $(1 \mathrm{mmol})$ and hydrazine hydrate $(1.5 \mathrm{mmol})$, aldehyde
(1 mmol), malononitrile ( $1 \mathrm{mmol})$, and a catalytic amount of $\mathrm{ZnO}$ nanoparticles ( $5 \mathrm{~mol} \%$ ) were successively added. The resulting suspension was stirred and heated at $70^{\circ} \mathrm{C}$ temperature for appropriate reaction time as specified in (Table 1). The progress of reaction was monitored by TLC (30\% EA: hexane). After completion of the reaction as monitored by TLC, the reaction mass was cooled, filtered off, and washed with hot ethanol $(5 \mathrm{~mL})$ to separate the product from the catalyst. The ethanol from the filtrate was allowed to evaporate at room temperature to get the crystals of product which were then subsequently washed with a mixture of $(30 \%$ EA: hexane) to afford the pure products. below.

The spectral data of principal compounds is represented 6-Amino-2,4-dihydro-3-methyl-4-phenylpyrano[2,3-c]pyrazole-5-carbonitrile (Entry 1, Table 1). White solid, M.P. 243$245^{\circ} \mathrm{C}$; ${ }^{1} \mathrm{H}$ NMR (400 MHz, DMSO-d 6 ) $\delta$ ppm $12.10(\mathrm{~s}, 1 \mathrm{H})$, 7.10-7.40 (m, 5H), 6.85 (s, br, 2H), 4.60 (s, 1H), 1.78 (s, 3H); IR $(\mathrm{KBr}) \mathrm{cm}^{-1} 3410,3356,3167,2990,1646,1596,1399,1276$, 870; ES-MS $m / z: 253(\mathrm{M}+1)$.

6-Amino-4-(4-chlorophenyl)-3-methyl-2,4-dihydropyrano[2, 3-c]pyrazole-5-carbonitrile (Entry 2, Table 1). Off-white solid, M.P. $233-235^{\circ} \mathrm{C}$; ${ }^{1} \mathrm{H}$ NMR $(400 \mathrm{MHz}$, DMSO-d 6 ) $\delta \mathrm{ppm}$ 12.15 (s, 1H), 7.10-7.40 (m, 4H), 6.95 (s, br, 2H), 4.63 (s, 1H), 1.80 (s, 3H); IR (KBr) cm ${ }^{-1} 3478,3035,2985,2193,1647,1596$, 1398, 1284, 870; ES-MS m/z: $287(\mathrm{M}+1)$.

6-Amino-4-(4-N,N-dimethylaminophenyl)-3-methyl-2,4-dihydropyrano[2,3-c]pyrazole-5-carbonitrile (Entry 3, Table 1). Yellow solid, M.P. $234-235^{\circ} \mathrm{C}$; ${ }^{1} \mathrm{H}$ NMR (400 MHz, DMSO$\left.\mathrm{d}_{6}\right) \delta \mathrm{ppm} 12.10(\mathrm{~s}, 1 \mathrm{H}), 6.70-7.15(\mathrm{~m}, 4 \mathrm{H}) ; 6.55(\mathrm{~s}, \mathrm{br}, 2 \mathrm{H})$, $4.40(\mathrm{~s}, 1 \mathrm{H}) ; 2.85(\mathrm{~s}, 6 \mathrm{H}), 1.78(\mathrm{~s}, 3 \mathrm{H})$; IR $(\mathrm{KBr}) \mathrm{cm}^{-1} 3385$, 3172, 2957, 2189, 1644, 1601, 1397, 1279, 868; ES-MS m/z: 296 $(\mathrm{M}+1)$.

6-Amino-4-(4-thiomethylphenyl)-3-methyl-2,4-dihydropyrano[2,3-c]pyrazole-5-carbonitrile (Entry 4, Table 1). Pale yellow solid, M.P. $242-244^{\circ} \mathrm{C}$; ${ }^{1} \mathrm{H}$ NMR $(400 \mathrm{MHz}$, DMSO$\left.\mathrm{d}_{6}\right) \delta \mathrm{ppm} 12.10(\mathrm{~s}, 1 \mathrm{H}), 7.10-7.35(\mathrm{~m}, 4 \mathrm{H}), 6.95$ (s, br, 2H), $4.58(\mathrm{~s}, 1 \mathrm{H}), 2.47(\mathrm{~s}, 3 \mathrm{H}), 1.80(\mathrm{~s}, 3 \mathrm{H})$; IR $(\mathrm{KBr}) \mathrm{cm}^{-1} 3482$, 3035, 2985, 2190, 1597, 1391, 1279, 851; ES-MS m/z: 299 (M + $1)$.

4.2. Morphology and Structural Investigations of $\mathrm{ZnO}$ Nanoparticles. The morphology and structural investigations of the catalyst were studied with XRD, TEM, and FTIR analyses. 


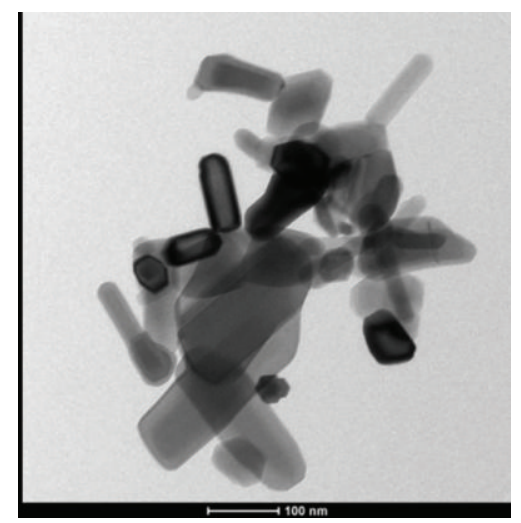

(a)

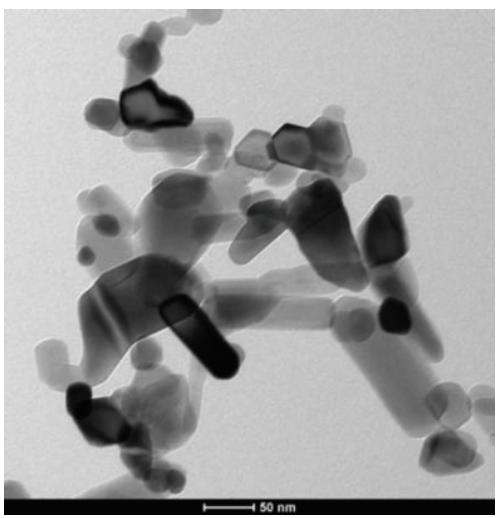

(b)

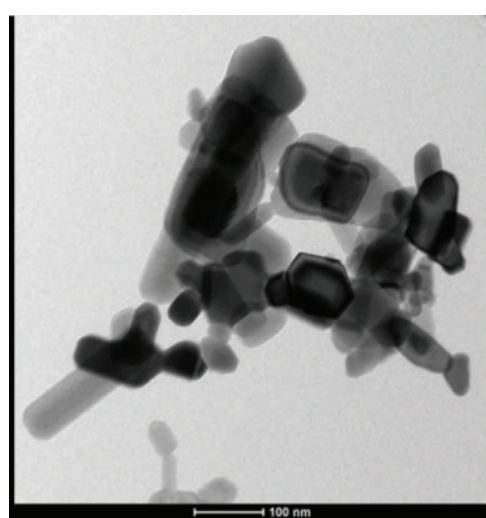

(c)

Figure 3: TEM images of the nano-ZnO.

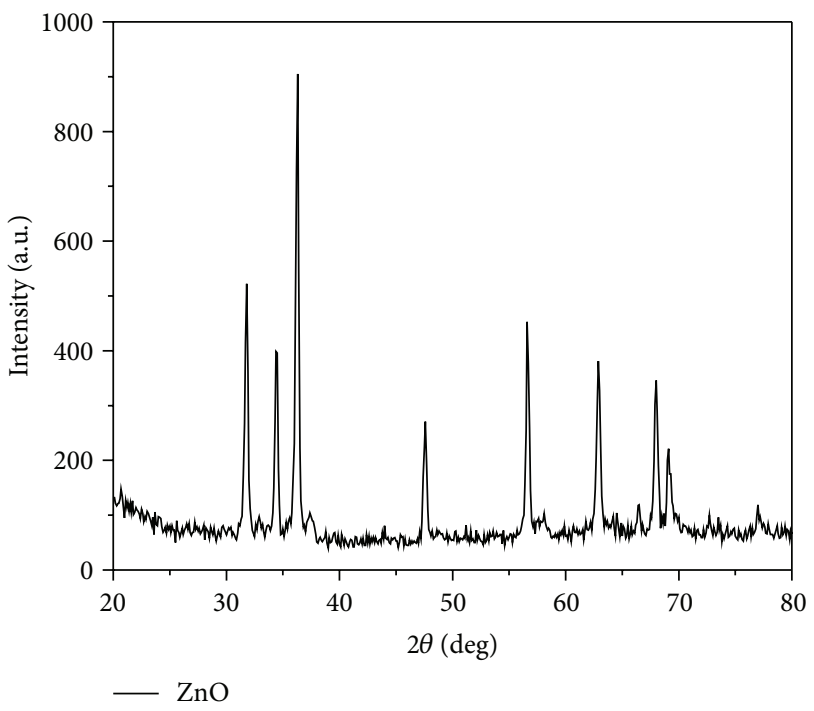

FIGURE 4: XRD of nano-ZnO.

4.2.1. TEM. The images in Figure 3 indicate that the particle size of the crystalline $\mathrm{ZnO}$ nanoparticles is in the range of $50-100 \mathrm{~nm}$. This small particle size of the nanocrystalline $\mathrm{ZnO}$ provides large surface area to the catalyst and assists for enhancing the rate of product formation.

4.2.2. XRD. XRD studies of nano- $\mathrm{ZnO}$ showed a characteristic pattern as shown in Figure 4. Diffraction peaks present at $2 \theta$ values of $32.08,34.74,36.64,48.04,57.04,63.22,68.28$, and 69.24 correspond to (100), (002), (101), (102), (110), (103), (200), and (201) planes, respectively. The strongest peak at $2 \theta=36.64$ belongs to the (101) plane. No impurity peaks were detected. It indicates good crystalline-nature the catalyst.

4.2.3. FTIR. FTIR spectrum was recorded on a Shimadzu 8400 s spectrophotometer from samples in $\mathrm{KBr}$ pellets. Normally the IR spectra of $\mathrm{ZnO}$ sample particles are influenced

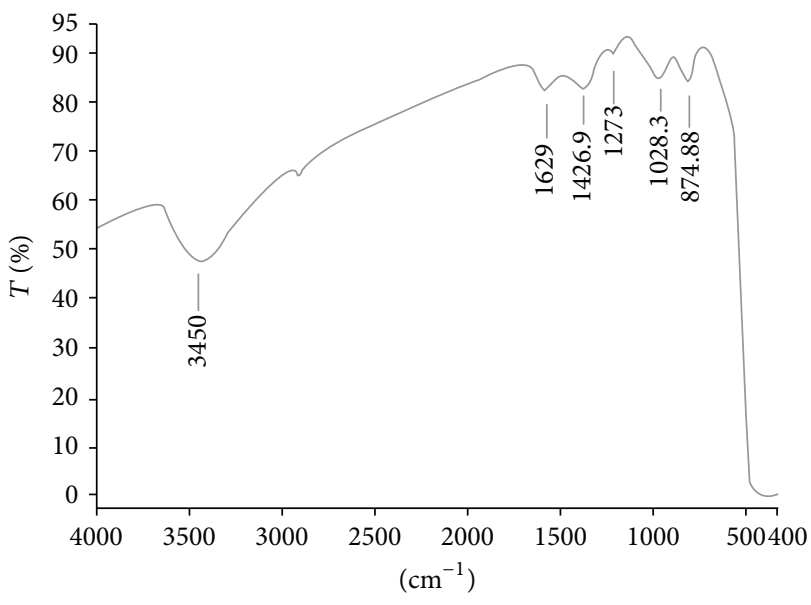

FIGURE 5: FTIR spectrum of nano-ZnO.

by morphology and the particle size. Figure 5 illustrates the FTIR spectrum of the $\mathrm{ZnO}$ particles.

\section{Acknowledgments}

The authors are thankful to the Principal, Deogiri College Aurangabad, for providing laboratory facilities and constant encouragement during the work. Sunil U. Tekale sincerely thanks the Department of Physics, Pune University for providing the Sophisticated Analytical Instrument Facility (SAIF).

\section{References}

[1] J. Jiang, H.-D. Xu, J.-B. Xi et al., "Diastereoselectively switchable enantioselective trapping of carbamate ammonium ylides with imines," Journal of the American Chemical Society, vol. 133, no. 22, pp. 8428-8431, 2011.

[2] C. Kalinski, H. Lemoine, J. Schmidt et al., "Multicomponent reactions as a powerful tool for generic drug synthesis," Synthesis, no. 24, pp. 4007-4011, 2008. 
[3] S. R. Roy, P. S. Jadhavar, K. Seth, K. K. Sharma, and A. K. Chakraborti, "Organocatalytic application of ionic liquids: [bmim $]\left[\mathrm{MeSO}_{4}\right]$ as a recyclable organocatalyst in the multicomponent reaction for the preparation of dihydropyrimidinones and -thiones," Synthesis, no. 14, pp. 2261-2267, 2011.

[4] R. Mallepalli, L. Yeramanchi, R. Bantu, and L. Nagarapu, "Polyethylene glycol (PEG-400) as an efficient and recyclable reaction medium for the one-pot synthesis of $\mathrm{N}$-substituted azepines under catalyst-free conditions," Synlett, no. 18, pp. 2730-2732, 2011.

[5] J. A. Weeden, R. Huang, K. D. Galloway, P. W. Gingrich, and B. J. Frost, "The Suzuki reaction in aqueous media promoted by $\mathrm{p}$, N Ligands," Molecules, vol. 16, no. 8, pp. 6215-6231, 2011.

[6] I. Kanizsai, S. Gyónfalvi, Z. Szakonyi, R. Sillanpää, and F. Fülöp, "Synthesis of bi- and tricyclic $\beta$-lactam libraries in aqueous medium," Green Chemistry, vol. 9, no. 4, pp. 357-360, 2007.

[7] S. B. Sapkal, K. F. Shelke, B. B. Shingate, and M. S. Shingare, "Nickel nanoparticle-catalyzed facile and efficient one-pot synthesis of polyhydroquinoline derivatives via Hantzsch condensation under solvent-free conditions," Tetrahedron Letters, vol. 50, no. 15, pp. 1754-1756, 2009.

[8] S. W. Kshirsagar, N. R. Patil, and S. D. Samant, "Mg-Al hydrotalcite as a first heterogeneous basic catalyst for the synthesis of 4H-pyrano[2,3-c]pyrazoles through a four-component reaction," Synthetic Communications, vol. 41, no. 9, pp. 13201325, 2011.

[9] F. M. Moghaddam, H. Saeidian, Z. Mirjafary, and A. Sadeghi, "Rapid and efficient one-pot synthesis of 1,4-dihydropyridine and polyhydroquinoline derivatives through the Hantzsch four component condensation by zinc oxide," Journal of the Iranian Chemical Society, vol. 6, no. 2, pp. 317-324, 2009.

[10] D. I. MaGee, M. Dabiri, P. Salehi, and L. Torkian, "Highly efficient one-pot three-component Mannich reaction catalyzed by ZnO-nanoparticles in water," Arkivoc, vol. 11, pp. 156-164, 2011.

[11] A. H. Mandour, E. R. El-Sawy, M. S. Ebaid, and S. M. Hassan, "Synthesis and potential biological activity of some novel 3[(N-substituted indol-3-yl)methyleneamino]-6-amino-4-arylpyrano(2,3-c)pyrazole-5-carbonitriles and 3,6-diamino-4-(Nsubstituted indol-3-yl)pyrano(2,3-c)pyrazole-5- carbonitriles," Acta Pharmaceutica, vol. 62, no. 1, pp. 15-30, 2012.

[12] N. Foloppe, L. M. Fisher, R. Howes, A. Potter, A. G. S. Robertson, and A. E. Surgenor, "Identification of chemically diverse Chk1 inhibitors by receptor-based virtual screening," Bioorganic and Medicinal Chemistry, vol. 14, no. 14, pp. 47924802, 2006.

[13] G. Vasuki and K. Kumaravel, "Rapid four-component reactions in water: Synthesis of pyranopyrazoles," Tetrahedron Letters, vol. 49, no. 39, pp. 5636-5638, 2008.

[14] M. E. A. Zaki, H. A. Soliman, O. A. Hiekal, and A. E. Z. Rashad, "Pyrazolopyranopyrimidines as a class of anti-inflammatory agents," Naturforsch C, vol. 61, pp. 1-5, 2006.

[15] F. M. Abdelrazek, P. Metz, N. H. Metwally, and S. F. ElMahrouky, "Synthesis and molluscicidal activity of new cinnoline and pyrano [2,3-c]pyrazole derivatives," Archiv der Pharmazie, vol. 339, no. 8, pp. 456-460, 2006.

[16] S. A. El-Assiery, G. H. Sayed, and A. Fouda, "Synthesis of some new annulated pyrazolo-pyrido (or pyrano) pyrimidine, pyrazolopyridine and pyranopyrazole derivatives," Acta Pharmaceutica, vol. 54, no. 2, pp. 143-150, 2004.
[17] J. M. Khurana, B. Nand, and S. Kumar, "Rapid synthesis of polyfunctionalized pyrano[2,3-c]pyrazoles via multicomponent condensation in room-temperature ionic liquids," Synthetic Communications, vol. 41, no. 3, pp. 405-410, 2011.

[18] D. Shi, J. Mou, Q. Zhuang, L. Niu, N. Wu, and X. Wang, “Threecomponent one-pot synthesis of 1,4-dihydropyrano[2,3-c] pyrazole derivatives in aqueous media," Synthetic Communications, vol. 34, no. 24, pp. 4557-4563, 2004.

[19] T.-S. Jin, R.-Q. Zhao, and T.-S. Li, “An one-pot three-component process for the synthesis of 6-amino-4-aryl-5-cyano-3-methyl1-phenyl-1,4-dihydropyrano[2,3-c]pyrazoles in aqueous media," Arkivoc, vol. 2006, no. 11, pp. 176-182, 2006.

[20] H. V. Chavan, S. B. Babar, R. U. Hoval, and B. P. Bandgar, "Rapid one-pot, four component synthesis of pyranopyrazoles using heteropolyacid under solvent-free condition," Bulletin of the Korean Chemical Society, vol. 32, no. 11, pp. 3963-3966, 2011.

[21] H. Mecadon, M. R. Rohman, M. Rajbangshi, and B. Myrboh, “ $\gamma$ alumina as a recyclable catalyst for the four-component synthesis of 6-amino-4-alkyl/aryl-3-methyl-2,4-dihydropyrano[2,3c]pyrazole-5- carbonitriles in aqueous medium," Tetrahedron Letters, vol. 52, no. 19, pp. 2523-2525, 2011.

[22] Y. Peng, G. Song, and R. Dou, "Surface cleaning under combined microwave and ultrasound irradiation: Flash synthesis of $4 \mathrm{H}$-pyrano[2,3-c]pyrazoles in aqueous media," Green Chemistry, vol. 8, no. 6, pp. 573-575, 2006.

[23] S. N. Darandale, J. N. Sangshetti, and D. B. Shinde, "Ultrasound mediated, sodium bisulfite catalyzed, solvent free synthesis of 6-amino-3-methyl-4-substitued-2, 4-dihydropyrano[2, 3c] pyrazole-5-carbonitrile," Journal of the Korean Chemical Society, vol. 56, no. 3, pp. 328-3333, 2012.

[24] M. B. Madhusudana Reddy and M. A. Pasha, "One-pot, multicomponent synthesis of $4 \mathrm{H}$-pyrano[2,3-c]pyrazoles in water at $25^{\circ}$ C, Indian Journal of Chemistry B, vol. 51, no. 3, pp. 537-541, 2012.

[25] S. U. Tekale, S. S. Shisodia, S. S. Kauthale et al., "Micron particles of AlN/Al: Efficient, novel, and reusable heterogeneous catalyst for the synthesis of bis(indolyl)methanes," Synthetic Communications, vol. 1, no. 43, pp. 1849-1858, 2013. 

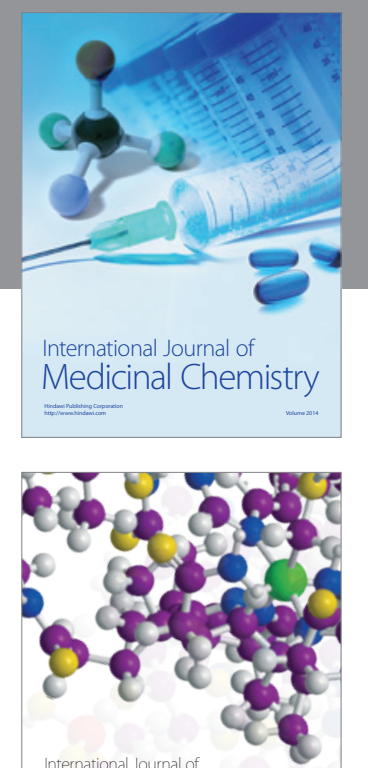

\section{Carbohydrate} Chemistry

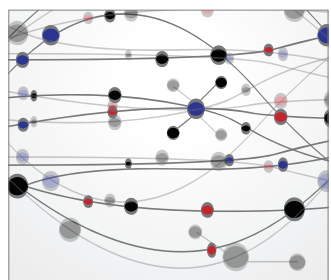

The Scientific World Journal
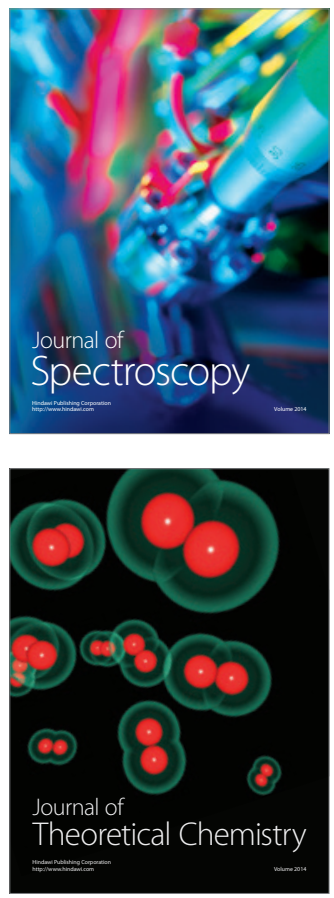
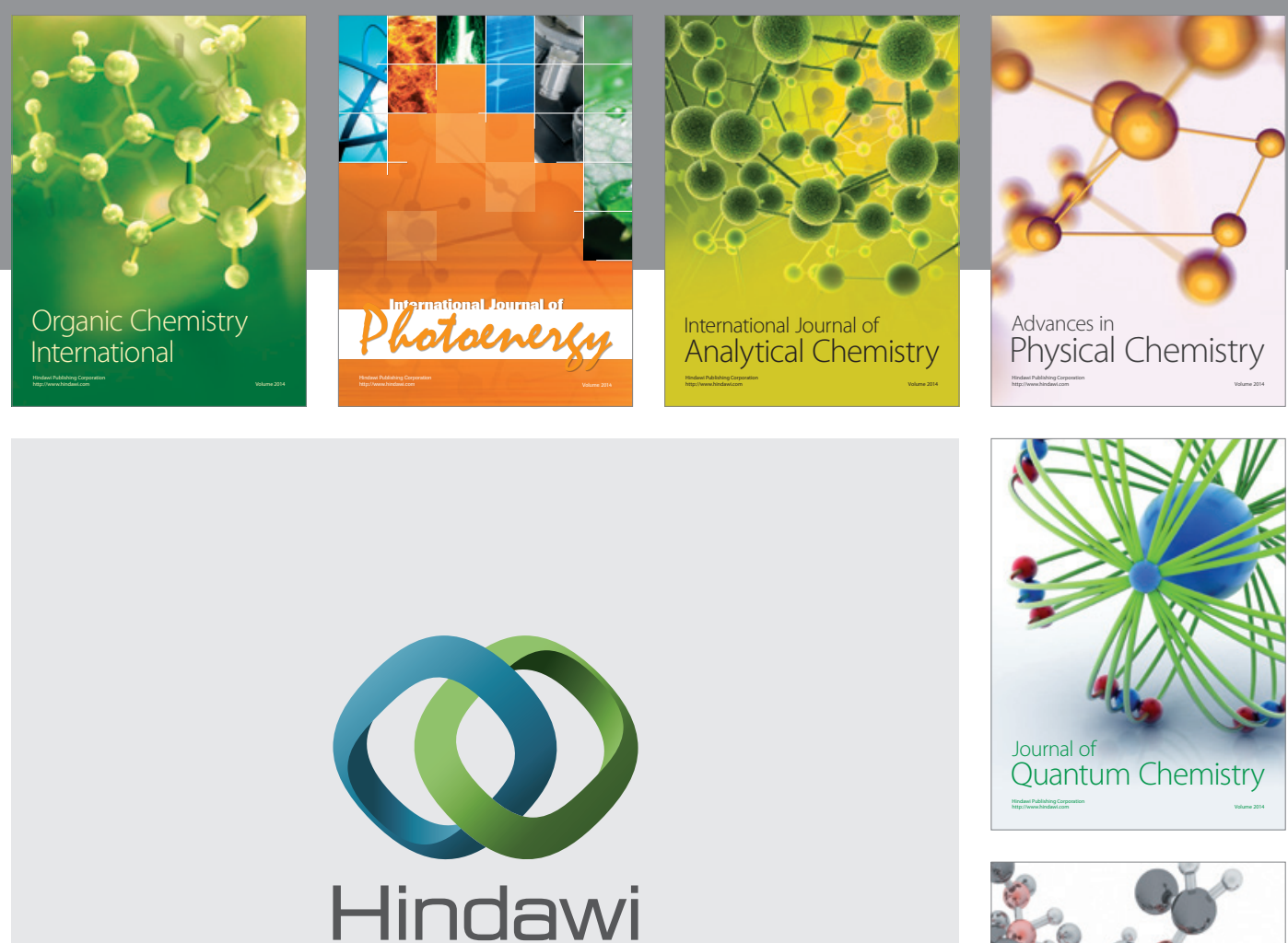

Submit your manuscripts at

http://www.hindawi.com

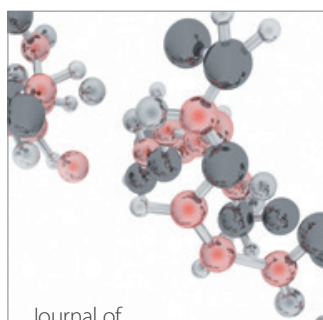

Analytical Methods

in Chemistry

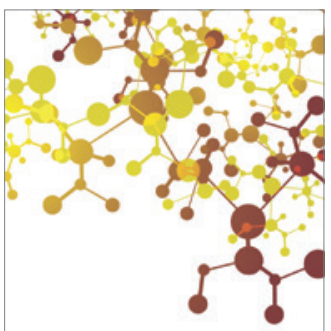

Journal of

Applied Chemistry

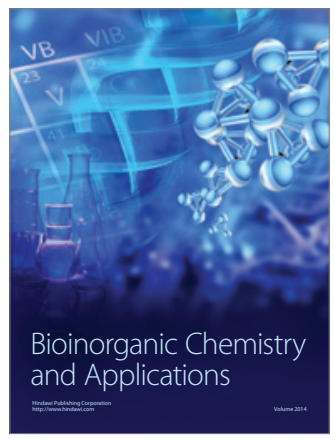

Inorganic Chemistry
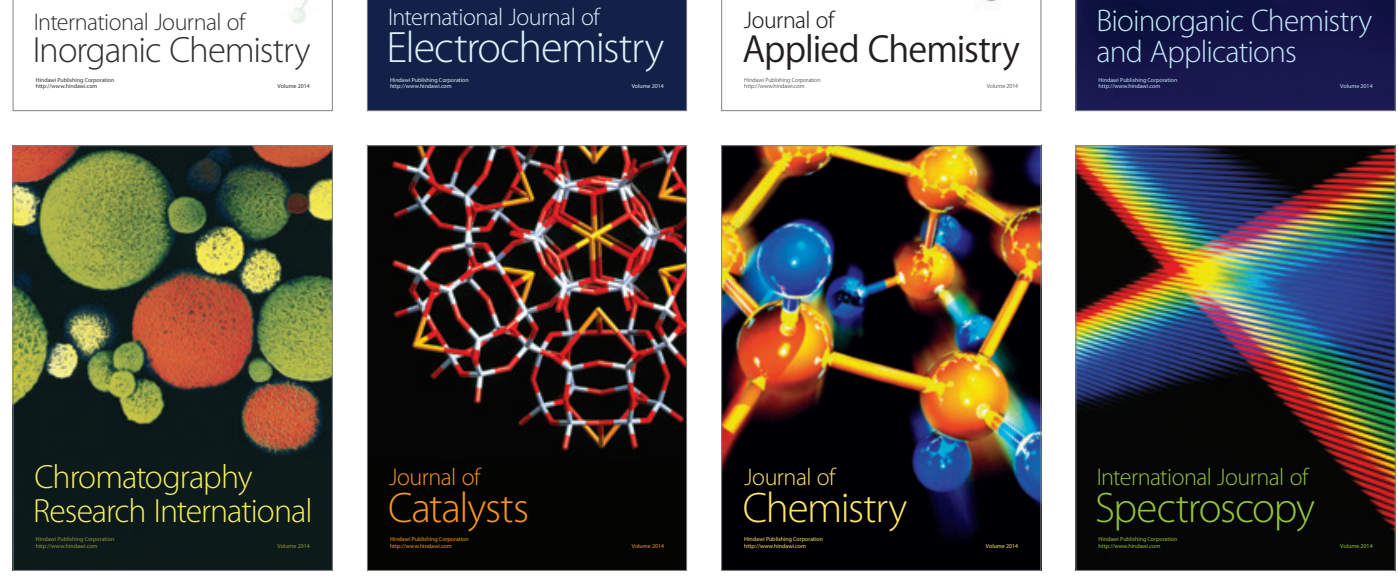